Aquat. Sci. 69 (2007) 584-589

1015-1621/07/040584-6

$\widehat{\text { Aquatic Sciences }}$

DOI 10.1007/s00027-007-0018-y

(C) Eawag, Dübendorf 2007

\title{
Erratum
}

Research Article

\section{Benthic diatoms of an Alpine stream/lake network in Switzerland}

\author{
Christopher T. Robinson and Barbara Kawecka
}

This is the corrected version of Appendix A of the above mentioned article that appeared in Aquat. Sci. 67 (2005) 492-506, DOI 10.1007/s00027-005-0783-4. 


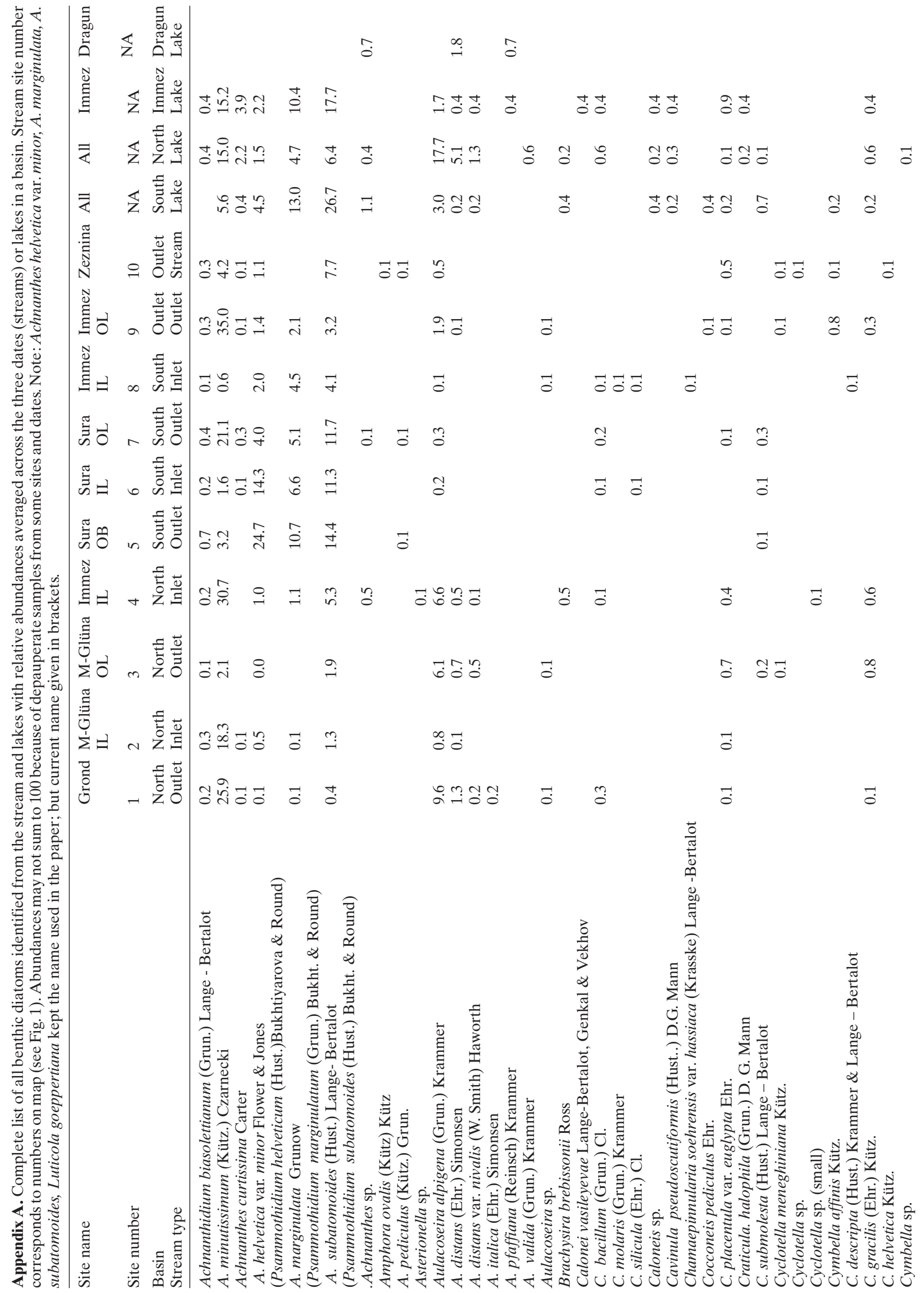




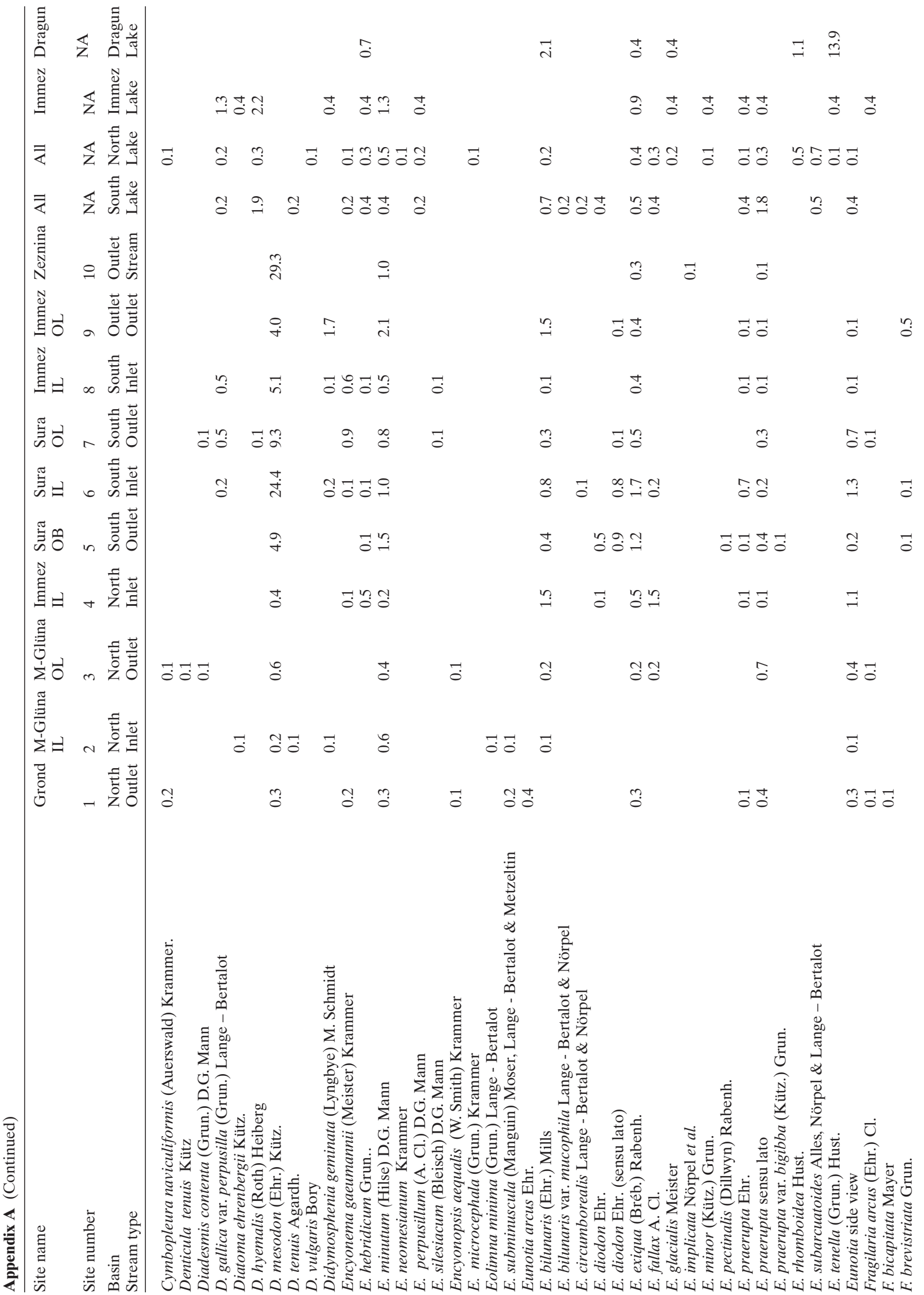




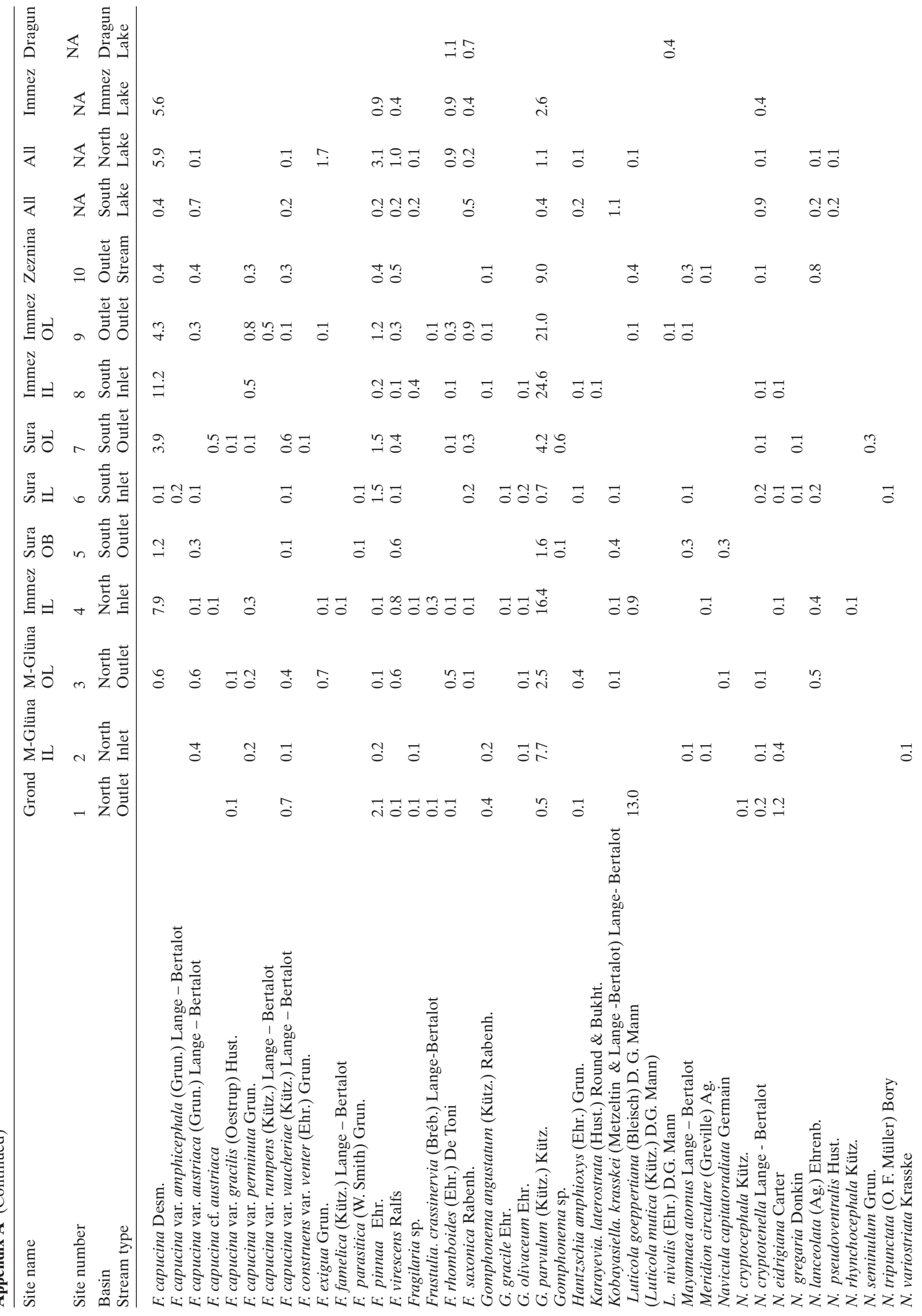




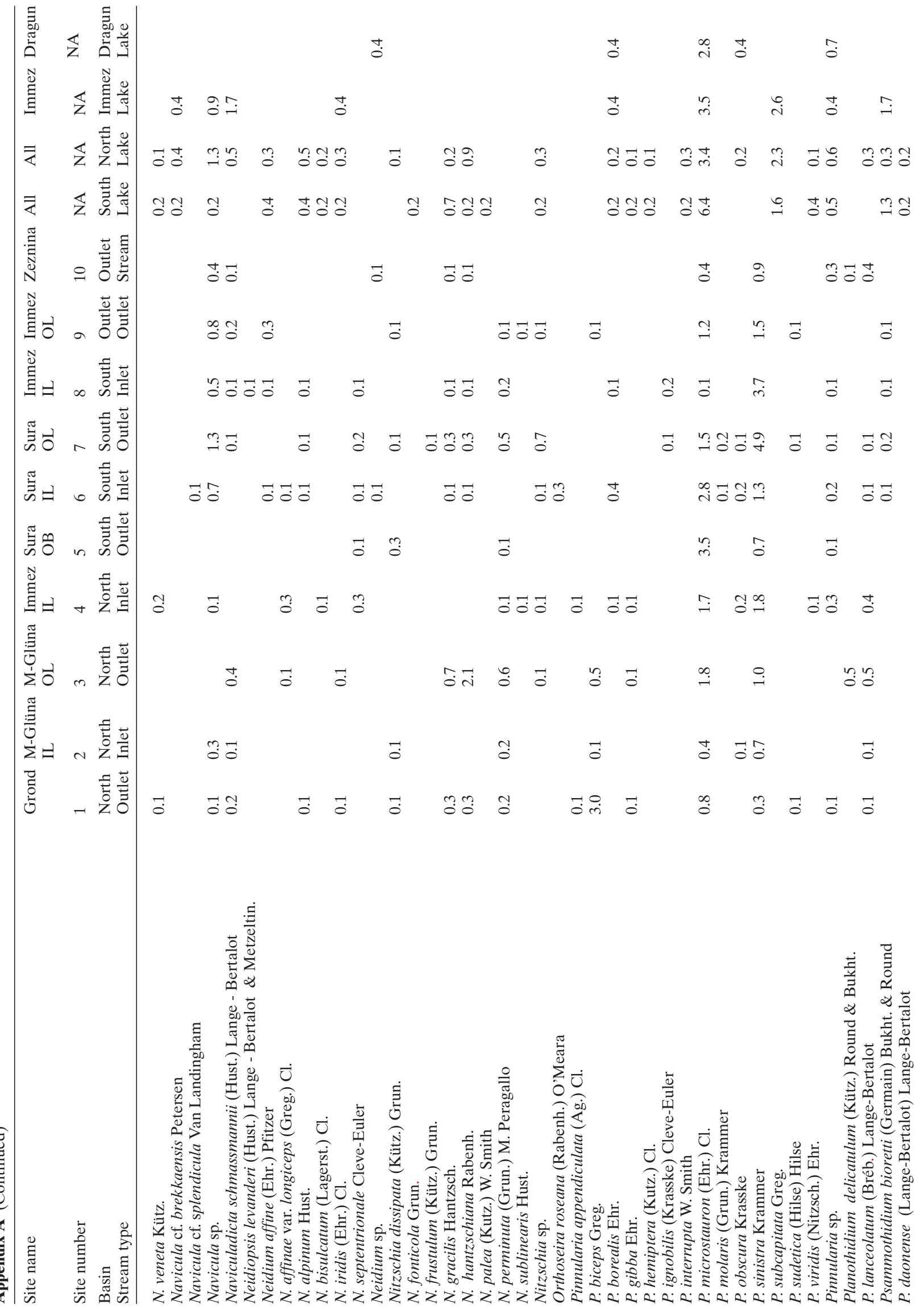




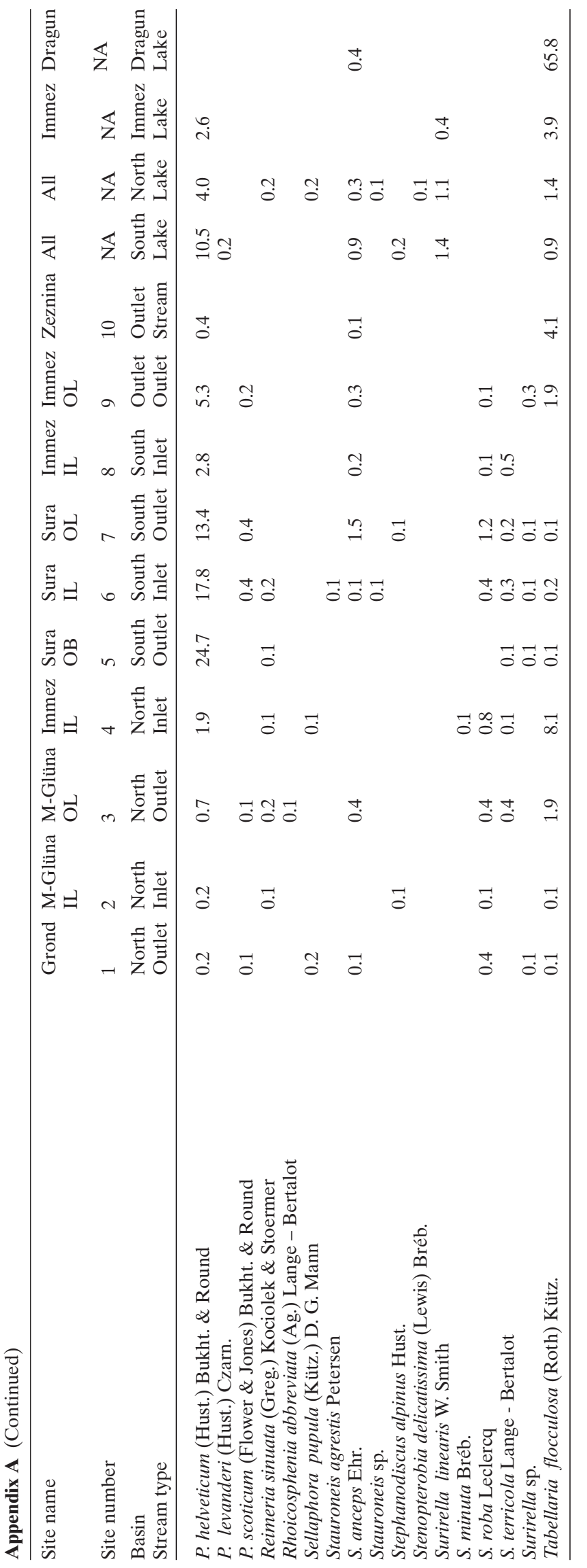

